\title{
Results of Uretero-cysto-neostomy in Vesico-ureteric Reflux in Infants and Children*
}

\author{
M. BETTEX, N. GENTON, and A. SCHÄRLI \\ From the Department of Paediatric Surgery, Children's Hospital, University of Berne, and the \\ Department of Paediatric Surgery, Hôpital Cantonal, University of Lausanne, Switzerland
}

As in other countries, vesico-ureteric reflux (VUR) provides a major problem of paediatric urology in Switzerland. The results of surgical treatment of VUR presented here are from two centres, Lausanne and Berne.

\section{Material and Methods}

In the 6-year period from 1959 to 1965,120 children with VUR were operated upon. Post-operatively, 103 have been submitted to one or more complete check-ups, including micturating cystography, intravenous pyelography, urine analysis and bacteriology and, in case of recurrence, cystoscopy. The follow-up period ranged from 6 months to $5 \frac{1}{2}$ years. In 64 cases the diagnosis was idiopathic VUR; in 23 children the VUR was secondary to an infravesical obstruction (bladder neck obstruction or urethral valves); in 14 a ureteric duplication was involved, and in 2 cases VUR was the result of a urethral ectopic ureter. All cases had a chronic or recurrent urinary infection.

All cases had conservative treatment before operation, and the obstruction cases were relieved of their obstruction before any reflux-preventing operation was undertaken. Three types of reflux-preventing operations were performed: (1) vesico-ureteric ostioplasty (Bischoff); (2) uretero-cysto-neostomy (Vest); and (3) uretero-cysto-neostomy of the Mathisen type.

The Bischoff type of operation is well known and does not need to be described (Fig. 1). In uretero-cystoneostomy as described by Vest the ureter is cut extravesically, just behind the ureteric orifice, pulled into the bladder through a small incision, and its wall turned back on itself to build a long nipple or papilla (Fig. 2). The Mathisen type of uretero-cysto-neostomy (Fig. 3) is derived from the uretero-sigmoidostomy described by Mathisen: the ureter is cut behind the bladder as in the Vest procedure; its end is covered with a pedunculated bladder-wall flap wrapped around it in the form of a cuff, and inserted into the bladder. A catheter of suitable size is left in the papillary orifice for at least one week.

\footnotetext{
* A paper read at a meeting of the British Association of Paediatric Surgeons in Edinburgh, July 1965.
}

\section{Results}

We have observed no severe complications in the immediate post-operative period, with any of the techniques. There has been no operative mortality. Most cases were submitted to a detailed check-up some 3 to 4 weeks after operation and the refluxpreventing effect was good in about $95 \%$ by all three techniques.

The late results, however, are not quite as good, in that some recurrences of reflux and some complicating ureteric obstructions have been observed (Table I). In our hands, the Bischoff type operation was not very satisfactory, since in only 8 of 14 cases $(57 \%$ ) was reflux prevented.

The Vest procedure was a little better with $71 \%$ of cases in which reflux was successfully prevented.

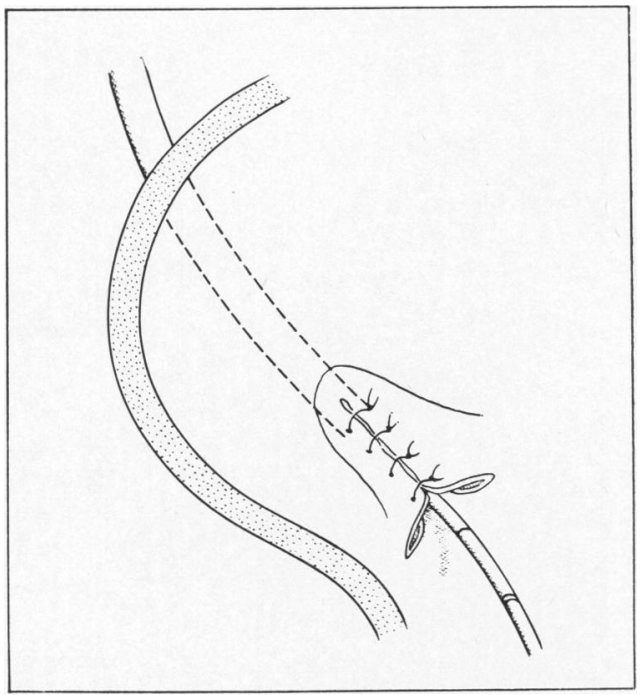

FIG. 1.-Reflux-preventing operation; Bischoff's procedure (vesico-ureteric ostioplasty). 


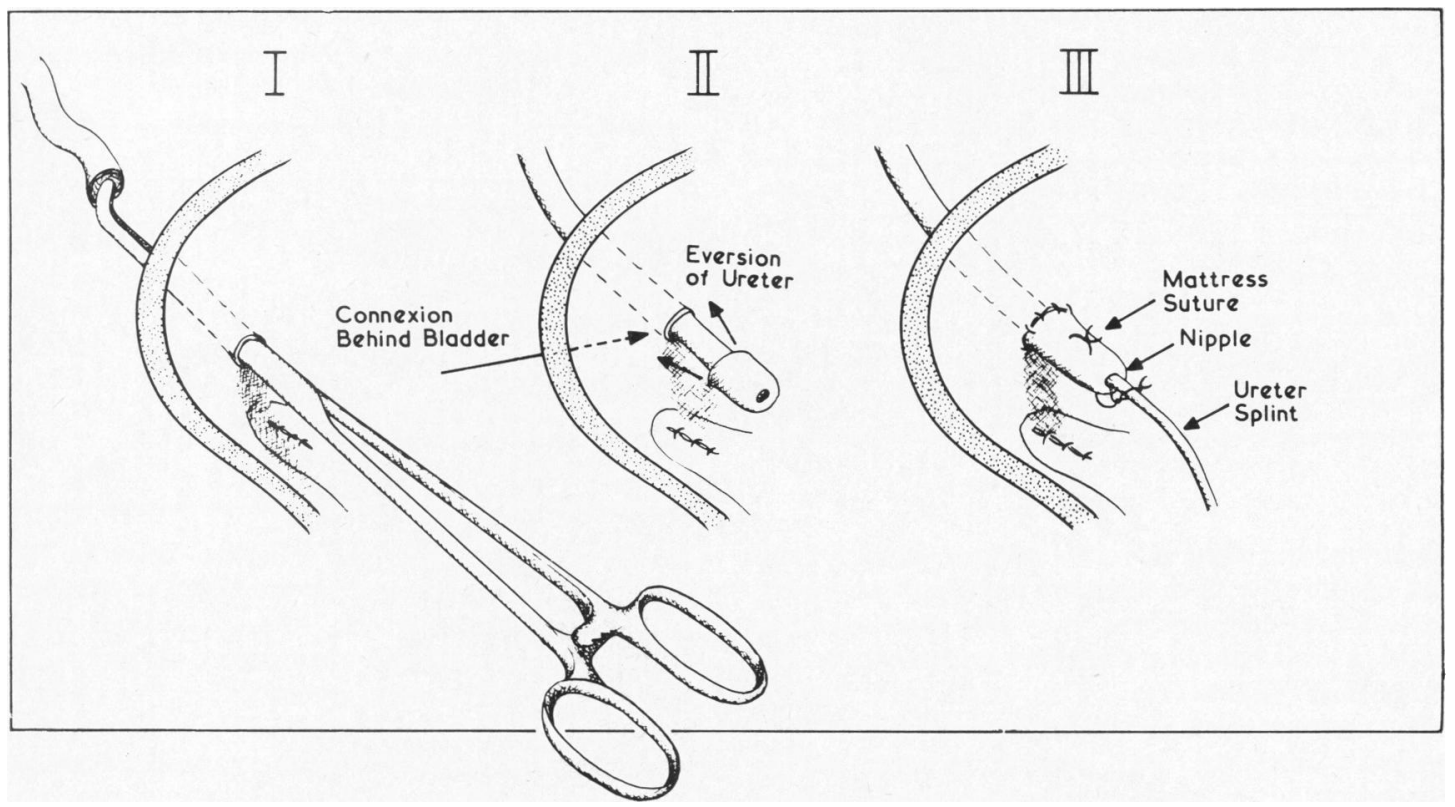

FIG. 2.-Uretero-cysto-neostomy; Vest's procedure.

There were, however, 3 cases with severe obstruction which later led to nephrectomy. Thus the over-all success rate was only $65 \%$.

The Mathisen type of operation prevented reflux well in the long run and the success rate was $79 \%$; but here too, the incidence of stenosis was not negligible, since out of 4 cases 2 necessitated nephrectomy and the other 2 had to be re-operated. The final success rate was thus only $75 \%$. The end results depend not only on the type of

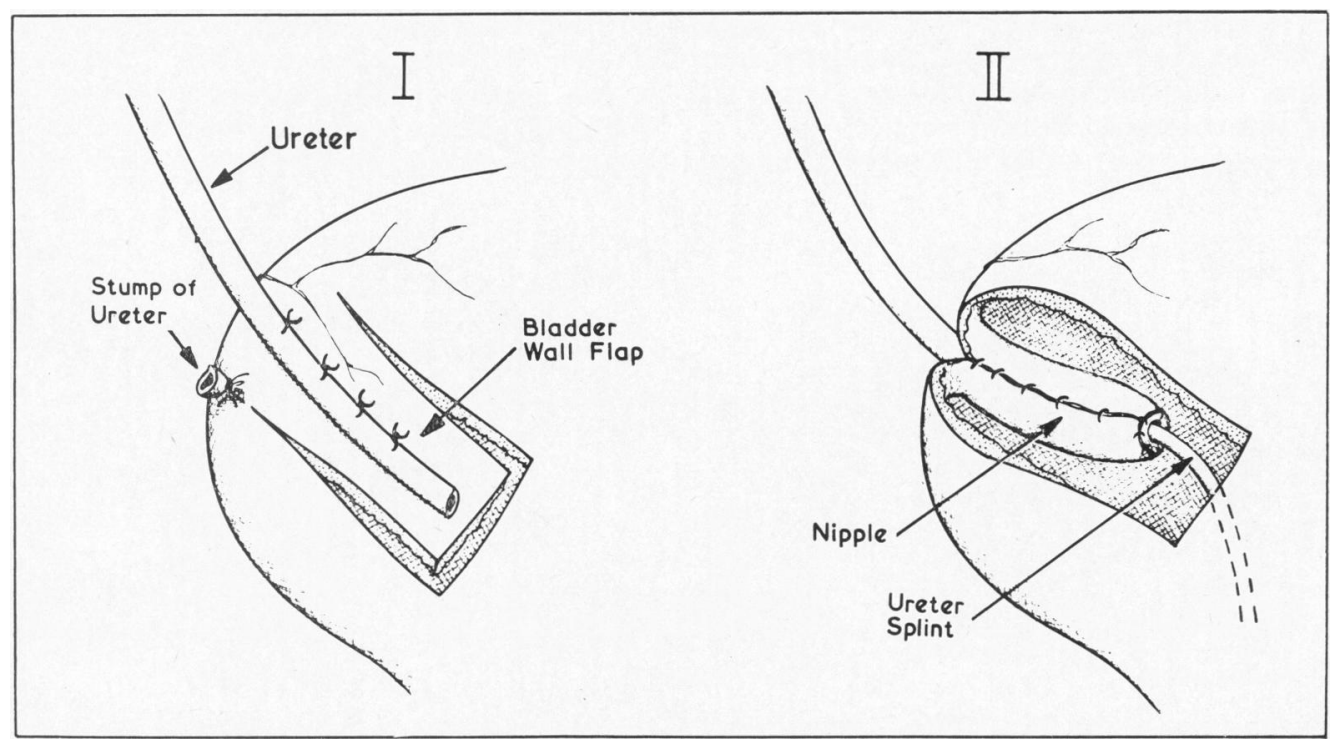

FIG. 3.-Uretero-cysto-neostomy; Mathisen's procedure. 
TABLE I

Late Results of Three Different

Reflux-preventing Operations

(141 ureters operated upon in 103 children)

\begin{tabular}{|c|c|c|c|c|}
\hline Type of Operation & Bischoff & Vest & Mathisen & Total \\
\hline $\begin{array}{l}\text { No. of ureters .. } \\
\text { No. of VUR recurrences } \\
\text { Successful prevention } \\
\text { of VUR } \\
\text { Complicating obstruc- }\end{array}$ & $\begin{array}{c}14 \\
6 \\
8 \\
(57 \%)\end{array}$ & $\begin{array}{c}26 \\
6 \\
20 \\
(71 \%)\end{array}$ & $\begin{array}{c}101 \\
22 \\
79 \\
(78 \%)\end{array}$ & $\begin{array}{c}141 \\
34 \\
107 \\
(76 \%)\end{array}$ \\
\hline 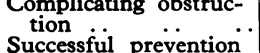 & 0 & 3 & 4 & 7 \\
\hline $\begin{array}{l}\text { of VUR and no ob- } \\
\text { struction }\end{array}$ & $\begin{array}{c}8 \\
(57 \%)\end{array}$ & $\begin{array}{c}17 \\
(65 \%)\end{array}$ & $\begin{array}{c}75 \\
(75 \%)\end{array}$ & $\begin{array}{c}100 \\
(71 \%)\end{array}$ \\
\hline
\end{tabular}

operation, but also, as many authors have pointed out, on the state of the urinary tract before surgery. In order to compare the pre- and post-operative status, a code based on a penalty points system was established (Table II). This takes into account reflux, ureteric dilatation, hydronephrosis, and pyelonephritic scarring, and awards 'penalty points' depending on the grade of the pathological changes. If a kidney became non-functional after operation, 20 penalty points were awarded, independently of other criteria.

If the scores before and after operation are compared, the Bischoff procedure (Fig. 4a) produces only a slight improvement, the shift to the low scores being moderate. After the Vest procedure (Fig. 4b), the improvement is more evident, but 3 cases are worse, with 20 penalty points.

After uretero-cysto-neostomy of the Mathisen type (Fig. 4c), the improvement of the penalty score is evident. The shift to the left is clear despite the 2 cases with non-functioning kidneys.

In order to see the bearing of the initial status on
TABLE II

\section{Penalty Points System for Pre- and Post-operative} Evaluation of VUR Cases

\begin{tabular}{|c|c|c|c|}
\hline & & & Penalty Points \\
\hline $\begin{array}{l}\text { VUR up to } 1 / 3 \text { of ureteric length } \\
\text { VUR up to } 2 / 3 \text { of ureteric length } \\
\text { VUR up to whole of ureteric leng }\end{array}$ & & $\begin{array}{l}\cdots \\
\cdots\end{array}$ & $\begin{array}{l}1 \\
2 \\
4\end{array}$ \\
\hline $\begin{array}{l}\text { Ureteric dilatation, moderate } \\
\text { Ureteric dilatation, gross }\end{array}$ & $\cdots$ & $\because$ & $\begin{array}{l}2 \\
4\end{array}$ \\
\hline $\begin{array}{ll}\text { Hydronephrosis, moderate } & \ldots \\
\text { Hydronephrosis, gross } & \ldots\end{array}$ & $\because$ & $\begin{array}{l}\cdots \\
\cdots\end{array}$ & $\begin{array}{l}2 \\
4\end{array}$ \\
\hline $\begin{array}{l}\text { Pyelonephritic scarring moderate } \\
\text { Pyelonephritic scarring gross }\end{array}$ & $\because$ & $\because$ & $\begin{array}{l}2 \\
4\end{array}$ \\
\hline Non-functional kidney & . & .. & 20 \\
\hline
\end{tabular}

the operative results, the relation between the penalty scores before and after operation has been investigated. In Fig. 5, the horizontal lines (ordinates) represent the score before operation, the abscissa the scores after operation. The oblique line marks an unchanged state. Thus the cases on the oblique line are unchanged, those on the left are improved, and those on the right are worse than before treatment. The hatched fields represent refluxing ureters.

With the Bischoff procedures (Fig. 5a) the initially relatively good cases are improved, the bad ones are not, and the incidence of recurrence of reflux is very high.

The initial state of the upper urinary tract in the group operated by the Vest technique (Fig. 5b) was obviously worse than in the Bischoff group. Nevertheless, the improvement is good in spite of the 6 cases with recurrence of reflux. The 3 kidneys which became non-functioning were already very impaired before surgery, as were 3 where the reflux recurred. In retrospect there had been inadequate
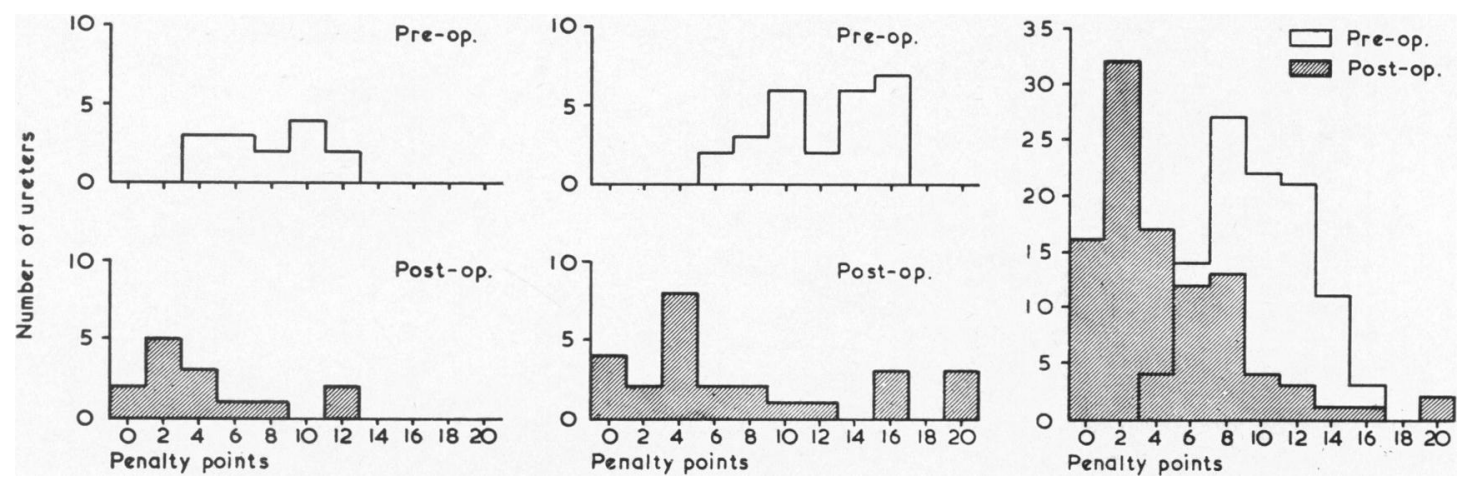

Fig. 4.-Penalty score before and after reflux-preventing operation (see text). procedure; (c) Mathisen's procedure.

(a) Bischoff's ostioplasty; (b) Vest's 
TABLE III

Incidence of Urinary Infection After Refluxpreventing Operation

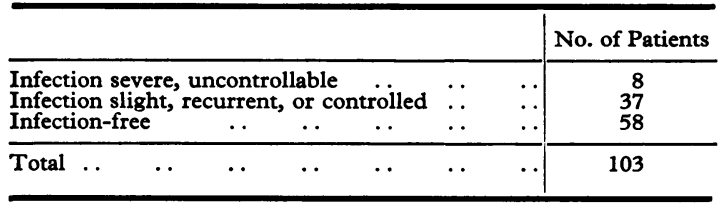

indications for reflux-preventing operation. As Williams and Eckstein (1965) point out, bad cases with adynamic ureters should not be submitted to reflux-preventing operations.

In the Mathisen group (Fig. 5c) all grades of deterioration of the upper urinary tract were present before operation. The shift toward improvement is obvious. In the 3 cases which became worse, this was due to a stenosis of the papilla (one in a ureteric duplication). But there have been 22 recurrences of reflux, distributed in all groups, independent of the severity of the pathological changes.

In most cases, radiology and cystoscopy identified the cause of the recurring reflux as an eversion of the papilla out of the bladder, both in the Vest and in the Mathisen groups. This complication is avoidable by the use of better technique. Some cases of recurring reflux were re-operated with the methods of Mathisen or Vest with good results. Others have been re-operated with the methods of Witzel or Grégoir with less favourable results.

All 5 cases with non-functioning kidneys required nephrectomy (heminephrectomy in one case of duplication of the ureter). In 2 patients with recurring reflux and a very bad score, urine was diverted through an ileal loop bladder, in order to save the renal function. In 4 cases of stenosis of the papilla, operation was repeated, but the results were rather poor.

All our cases were infected before operation. After operation, over $50 \%$ have sterile urine and need no treatment. Most of the cases still infected are controlled with antibiotics or sulphonamides. Only 8 cases with bad scores have uncontrollable urinary infections (Table III).

\section{Conclusion}

Uretero-cysto-neostomy with formation of a papilla of the Mathisen type is a good reflux-preventing operation. The Vest procedure can give good results too, but seems less effective in the long run. The recurrences of reflux observed have been largely due to a technical error-bad fixation of the papilla, but nevertheless uretero-cysto-neostomy with formation of a long nipple seems to be a sound procedure.
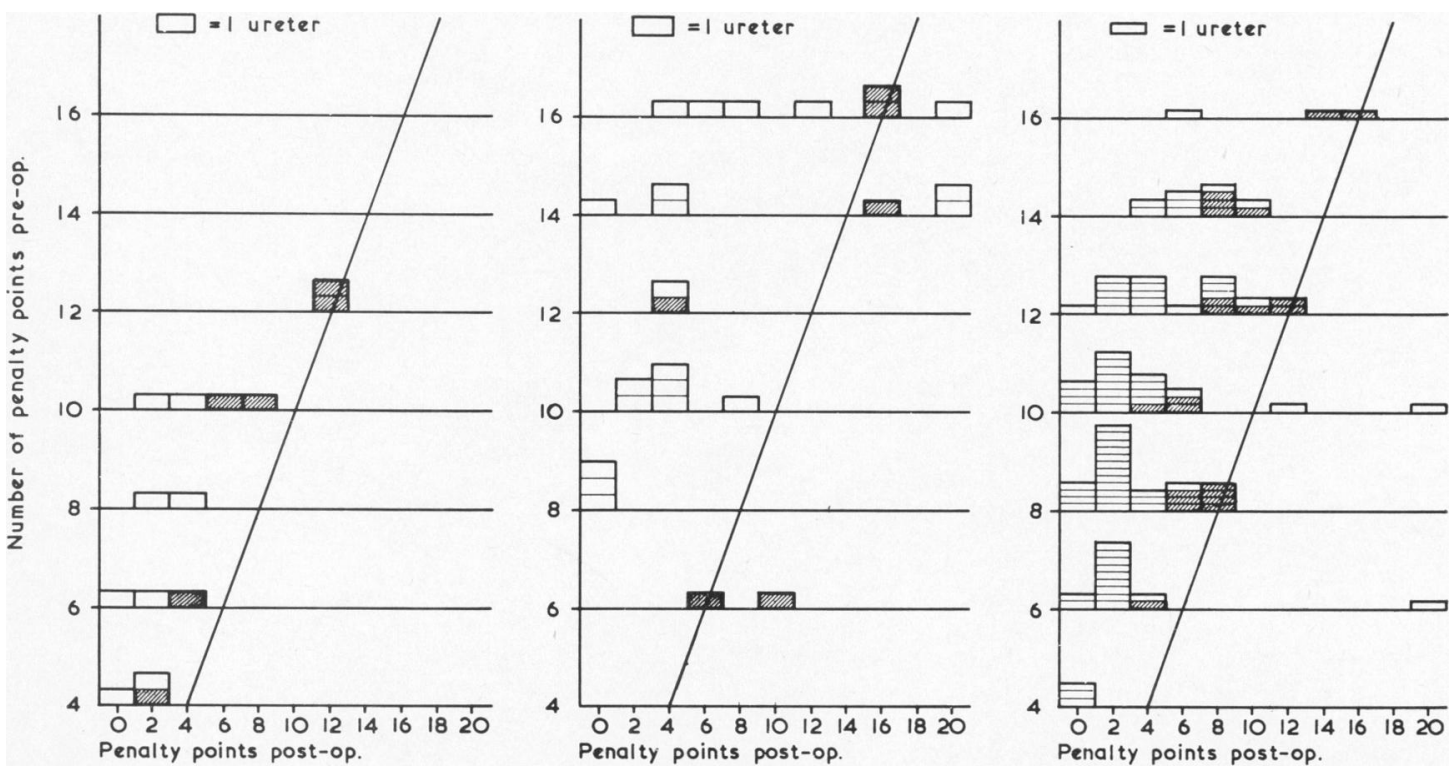

FIG. 5.-Score shift after reflux-preventing operation related to pre-operative score (see text). (a) Bischoff's procedure; (b) Vest's procedure; (c) Mathisen's procedure. The hatched fields represent refluxing ureters. 
The over-all results are partly dependent on the operation itself, but even more so on the status of the urinary apparatus before operation. The selection of cases for reflux-preventing operations is thus most important.

We are grateful to Mrs. Micheline Bettex-Galland, Ph.D., for invaluable assistance in the preparation of this paper and for the illustrations.
BIBLIOGRAPHY

Bettex, M. (1965a). Ueber den vesiko-ureteralen Reflux beim Säugling und Kind. Hans Huber, Berne and Stuttgart. (1965b). Ueber die chirurgische Behandlung des vesikoureteralen Refluxes im Kindesalter. $Z$. Kinderchir., 2, 74.

, and Bettex-Galland, M. (1965). Vesico-ureteric reflux in infants and children. Pediat. Digest, 7, 45.

Genton, N. (1961). Traitement des anomalies de la jonction urétéro-vésicale de l'enfant par urétéro-néocystostomie selon Mathisen. Helv. chir. Acta, 28, 617.

Williams, D. I., and Eckstein, H. B. (1965). Surgical treatment of reflux in children. Brit. F. Urol., 37, 13. 